\title{
M. DESHAIES, Espaces et sociétés slaves
}

coll. « Carrefours » Paris : Ellipses, 2005

\section{Stéphane Rosière}

\section{OpenEdition}

\section{Journals}

Édition électronique

URL : http://journals.openedition.org/rge/1381

DOI : $10.4000 /$ rge. 1381

ISSN : 2108-6478

\section{Éditeur}

Association des géographes de l'Est

Édition imprimée

Date de publication : 1 janvier 2006

ISSN : 0035-3213

\section{Référence électronique}

Stéphane Rosière, "M. DESHAIEs, Espaces et sociétés slaves », Revue Géographique de l'Est [En ligne], vol. 46 / 1-2 | 2006, mis en ligne le 17 décembre 2009, consulté le 25 septembre 2020. URL : http:// journals.openedition.org/rge/1381 ; DOI : https://doi.org/10.4000/rge.1381

Ce document a été généré automatiquement le 25 septembre 2020.

Tous droits réservés 


\section{DESHAIES, Espaces et sociétés slaves}

coll. « Carrefours » Paris : Ellipses, 2005

Stéphane Rosière

RÉFÉRENCE

M. Deshaies, Espaces et sociétés slaves, coll. «Carrefours », Paris : Ellipses, 2005, 144 p. 
1 Reprenant la tradition des «études slaves" dont l'historien Ernest Denis (1849-1921) avait été l'initiateur, Michel Deshaies nous offre avec ce livre utile un panorama renouvelé de cette "autre Europe », selon l'expression de Czeslaw Milosz, que la disparition du « rideau de fer » n'a guère rendu plus familière. Cette ignorance est pourtant paradoxale alors que, comme le rappelle l'auteur, «les Slaves forment (...) le plus important groupe ethnolinguistique européen (...) avec près de 300 millions de personnes » (p. 5).

2 La première partie revient sur «l'identité et la diversité de l'aire culturelle slave » (pp. 13-44), la seconde sur «la difficile construction des États nationaux» (pp. 45-80), la troisième sur "des sociétés deux

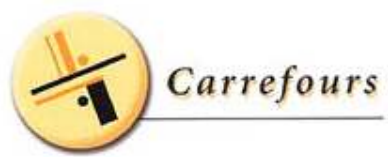

Espaces et sociétés slaves

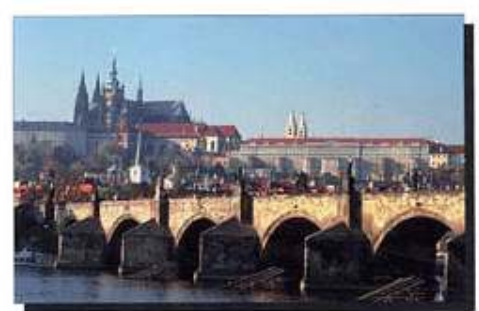

Michel Deshaies ellipses fois bouleversées» (pp. 81-104), et la quatrième sur la « transition » économique et politique contemporaine (pp. 105-138).

3 La proximité culturelle des peuples slaves repose surtout, comme le rappelle l'auteur, sur une proximité linguistique que mettent bien en exergue différents tableaux lexicaux comparatifs de quelques langues slaves (pp. 14-16). Cette proximité linguistique n'empêche pas de "profondes différences culturelles", ni des relations conflictuelles comme entre Polonais et Russes, ou Serbes et Croates. De ce point de vue, la proximité linguistique n'est pas un gage d'entente politique. M. Deshaies revient sur la formation du peuplement slave dans une fresque géo-historique qui va des «origines incertaines » au peuplement contemporain. Cette description s'appuie largement sur les travaux classiques en la matière qui font sans doute la part belle à une historiographie nationaliste triomphante depuis les années 1920 (cf. l'État de Samo, esquisse de la Tchécoslovaquie, argumentaire des Tchécoslovaques en 1918 justifiant la création de leur Etat et qui relève largement du mythe national, tout comme put l'être la Gaule pour la France). L'espace slave est ensuite présenté au travers de ses caractéristiques physiques de la grande plaine de l'Europe du Nord aux Balkans, des rives de la Baltique jusqu'à celles du Pacifique, le thème des grands axes de communications étant à cette occasion mis en exergue.

4 La difficile construction des Etats nationaux est fondée sur la description d'un « espace aux frontières internes longtemps fluctuantes ». L'idée de « relative stabilité des peuples» (p. 45) est-elle vraiment justifiée ? Certes, à petite échelle et sur les temps longs, les choses n'ont pas sensiblement changé depuis le $\mathrm{XI}^{\mathrm{e}}$ siècle, mais dans le détail ? Que de peuples éradiqués (les Juifs au cœur de cet espace "slave»), déplacés (Allemands, Polonais), expulsés (Turcs expulsés des Balkans depuis la fin du XIX ${ }^{\mathrm{e}}$ siècle, Albanais de la Serbie au XIX ${ }^{\mathrm{e}}$ et au début du XX $\mathrm{X}^{\mathrm{e}}$ siècle sauf au Kosovo, Polonais et Ukrainiens mutuellement échangés ou exterminés (1944-1946), sans parler des conséquences du «nettoyage ethnique » lors des guerres consécutives de l'éclatement de la fédération yougoslave (1991-1995). L'ampleur des traumatismes et de l'homogénéisation forcée du 
peuplement parait sous-estimée. L'instabilité des Etats est par contre bien mise en exergue - l'instabilité géographique des peuples a été d'ailleurs le corollaire de celle des Etats depuis le XIX ${ }^{e}$ siècle, les deux étant dialectiquement liés par la généralisation du principe d'Etat-nation qui fut appliqué dans une région au peuplement hétérogène. La figure 7 (p. 48) sur la durée d'existence des frontières en Europe centrale et orientale est, de ce point de vue, bienvenue et explicite : la densité du maillage politique exprime bien l'instabilité des territoires. Identités, influence allemande, et dominations étrangères sont ensuite envisagées. En ce qui concerne l'identité, on peut regretter que le cas de l'Eglise uniate, fruit du choc des identités orthodoxes et des impérialismes catholiques, ne soit pas mieux mis en exergue - il est cité à propos de la Biélorussie (p. 57), alors qu'il concerne surtout l'Ukraine occidentale et la Transylvanie actuelles. Et si l'espace slave est longtemps soumis à de multiples impérialismes... des puissances slaves dont la Pologne et la Russie en furent aussi parties prenantes. Le ressentiment contemporain des Lituaniens contre les Polonais se fonde ainsi sur une instrumentalisation contemporaine de ces dominations passées.

La troisième partie dresse un utile panorama des sociétés slaves contemporaines. L'impact du communisme (collectivisation, industrialisation) est rappelé. La transition politique est justement comparée à un "tremblement de terre" dans des pays où la tradition démocratique, à l'exception de l'ex-Tchécoslovaquie est faible ou nulle (exURSS). "Ces pays ont vécu en accéléré, sinon avec brutalité une évolution de l'organisation économique, de l'emploi et finalement de la vie quotidienne que les pays d'Europe occidentale ont connu au cours des trente dernières années" (p. 97). L'impact de cette transition brutale concerne autant la démographie (en chute libre), le chômage (corollaire de la libéralisation économique), que le niveau de vie marqué par un fort accroissement des gradients de revenus.

Une étude synthétique des douze Etats slaves contemporains clôt cette étude. Si la bibliographie ne cite pas un certain nombre d'auteurs français qui font référence en la matière (V. Rey, M.-C. Maurel), elle s'enrichit par contre d'auteurs allemands contemporains qui apparaissent beaucoup plus rarement dans les travaux français situation symptomatique d'une époque où la maitrise de la langue de Goethe est en recul, tout comme l'idéal européen? Puisse ce genre de travaux infléchir une tendance lourde. Au final, ce livre synthétique souffre sans doute des travers liés à son format (140 pages de texte) en étant parfois schématique ou rapide - peut-être l'ex-Union soviétique aurait-elle mérité un tome à part? -, néanmoins, il offre une excellente introduction à une aire culturelle encore méconnue et contribue au renouvellement de la recherche française sur cet espace.

\section{AUTEURS}

\section{STÉPHANE ROSIĖRE}

Université de Nancy 2 